that as their Dinner would take place on Monday next, the Society would, of course, not meet that evening, except in the freemasong' Tavern, where he hoped to see a very powerful muster.

CIRCULATION OF THE BLOOD IN THE VEINS.

\section{To the Editor of The Lancrt.}

SrR,-In the report of the proceedings of the Westminster Medical Society, for the 7 th of February, No. 285, Mr. Bennett offered some opinions relative to the circulation of the blood in the veits, and ap. peared to think them, either unnecessarily numerous and capacious, or that they performed some other function distinct from the mere passage of the blood. It appeared also that the generality of the members did not agree with Mr. Bennett's ideas on the subject; at the same time it does not appear that any satisfactory reasons were advanced in opposition to Mr. Bennett's opinions : indeed there appeared a deal of obscurity concerning the increased velocity of the blood through the veins, \&c. If the following observations on this subject may be thought not unworthy of a carner in "Trr: Lancet, I shall feel highly fiattered by their insertion. It may be said that $I$ have not offered any thing new in these observations; that is not my intention, but merely from what we already know of the circulation of the blood, and its mechanical contrivances, with the effects known to arise from a derangement of any of its modes of action, to deduce a sufficient reason against Mr. Bennett's opinion, and to show good grounds for believing that there does not exist a greater quantity of veins than is necessary to return the blood to the beart, and that they do not perforn any function distinct and independent of it. I am, Sir, Your obedient servant,

Feb. 26, 18\%9. $\Delta$.

It must be recollected that the artery is a highly active vessel, provided with muscular tibres, and consequently possessing great force in itself; the fluid in the artery has been forcibly expelled from the heart, onward to its destination, and this expulsion is kept up by the contractile power of the muscular fibres surrownding the artery. The vein, on the contrary, is an entirely passive reservoir, totally un provided with muscular fibres, consequently the blood flows to the heart, partly from the impulsive power given to it by the artery, and partly from its equality of pressure ; for by making an opening in to a vein, and introducing a tube, the blood will flow in whatever direction you choose to direct the tube; hence the use of valves to prevent the blood from regurgitating. It must, therefore, be seen that there exists a great diflerence in the force and rapidity of the flow of blood between the artery and the vein. If there were generally but one vein to an artery, the vein would be unequal to the task of conveging back the blood as fast as the artery expelled it; the balance could not be kept up, the heart would have sent forth more blood than it could procure again from its veins; the equilibrium would be destroyed. But we see that from the facility afforded to the return of the blood, and the mechanical contrivance of its con. duits, the hean $t$ is, in a manner, ennbled to regulate its admission. Of what great im. portance this is in the animal economy, fully appenrs from the arrangement of the vessels of the bead and spine; the blood is sent to the head by means of the vertebral and in. ternal carotid arteries, which last are not permitted to enter the cranium in a direct line, but are obliged to take an exceedingly tortuous course, opposing some degree of resistance to the flow of blond to the brain. But what is protided for its exit? Laroe sinuses, which, communicating with the internal jugular veins, afford an easy and im. mediate passage to the blood. In fine, let the immediate danger be remembered that would arise from an obstruation to the refux of the blood from the brain and spinal cord, and there can no longer appear a superfitity of veins for the mere passage of the blood.

\section{ERGOT OF RYE IN LTNGERING LABOUR,}

\section{To the Editor of The Lancer.}

$S_{I R},-B e i n g$ a reader of your invaluable Journal, and perusing your reports of the late discussion at the London Medical Society, on the effects of the secale cornutum, or ergot of rye, 1 beg leave to trouble you with a case in which I made use of the ergot. I was called to Mrs. Hitton, Chap. pel-street, of this place, who had been in labour for twenty-three hours. When I arrived $I$ found a debilitated woman, with lingering or ineffectual pains; upon examining per raginam, I found the linquor amnii dis harged, the os tince dilated, and well lubricated, the presentation natural. 1 wated two hours, and the pains still being ineffectual, I determined to try the ergot. I put only one scruple into four ounces of water, boiling it down to two; of this I gave her one half; ten minutes having elapsed, and the pains still weak, I gave ber 
the remaining portion; strong pains came on, or cireular motion of the forceps, they must, and in twenty-five minutes roth child and in the after part of the operation, to be explacenta were expelled. Had it not been tracted without injury to the jaw or fargs, for the ergot, she would, judging from cir- be lifted out in a direction perpendicular to cumstances, have been hours Inger. My their sockets.

opinion is, that the ergot ought not to be sed if the os uteri be not dilated, at least to the size of half-a-crown, or if the liquor amnii be not discharged, or if there be any preternatural presentation, or if the pains be totally wanting.

Your obedient servant,

Eduund Tayl r, Surgenn, Middleton, near Manchester. Middleton, Feb. 18, 18\%9.

3. That the forceps is the safer instrument of the two.

4. That fewer teeth are broken with it.

5. And, above all, that the application and use of it are muctr less painful than those of the key.

In prof of the last assertion, I Lave the concurrent and valuable testimony of many of my patients. who, having submitted to the application of both instruments, would not allow the key to be used afterwards, dreading, as they truly observed, "that horrible wrench."

EXTRACTION OF TEETH.

\section{To the Editor of THE LaNCET.}

SrR,-The only excuse I can find for the positive and illiberal remarks of your correspondent, Mr. J. De La Fons, respecting myself, is, that he only read a short para. graph or two of my paper on the Extrac. tion of Teeth. The laxge srceps, as I par. ticularly stated, are for the very large molar teeth only, the small one being generally used for teeth of all kinds. The large instrument is lengthened in the jaws, that is, in those parts extending from the joint to the short extremity, for the express purpose of making them more convenient to use, the loss of power being compensated by the additional thickness of it in the fore parts, which, however, adds but little to its bulk or length, this latter being precisely the same as the key; so that the "ludicrous extent" of it exists only in the imayination of the writer himself, who seems to have mistaken the word jaws for claws. It will be evident, upon a single perusal of his first paper, and a glance at the diagrams, that my opponent did not confine his remarks on the use of the key to the molar teeth; bat now his arguments are disputed, and his conclusions (not fucts) doubted, he has taken fresh ground, and wishes to make trial on them alone. There is no oceasion, but $I$ should have no objection to meet him there, not, certainly, as he somewhere sneeringly observes, in order to give publicity to defeat on either side, but for the laudable purnose of eliciting truth.

The following conclusions I believe to be founded on facts :-

1. That in 49 eases out of 50 , in which "the key is generally nsed," teeth of all kinds cau be safely and expeditiously ex. tracted with the forceps.

2. That whether teth are first loosened by the wrenoh of the key, or by the lateral

Let any person carefully examine the boasted diarram, and place in a similar one, not a conical, but such a tooth as I have now before me, whose fangs are half an inch in length, and $\frac{5}{8}$ of an inch in breadth from fano to fang, the diameter, at the neck, being no more than $\frac{3}{8}$ of an inch, when he will have ocular demonstration, that to be extracted skilfully, it must be raised perpen. dicularly out of the socket.

"I'alk of " sciolists," " torturing," and "cavillers," inded! Let Mr. De La Fons, before he attempts again to teach old practitioners, pay zome deference to the opinions of those who are not so ignorant as he supposes them.

Relying, Sir, on your usaal impartiality for the insertion of this, -I beg to say, that I am an admirer of your public spirit, and Your humble servant, J. Prowse.

Bristol, February 18, 1829.

\section{WEBB-STREET SCHOOL OF ANATOMY:}

\section{To the Editor of The Lancet.}

Sr $r,-A s$ you have inserted in THE T,ANcer, of the 1 thth inst., a communication from a pupil of the Wehib-street sehool, falsely accusing Mr. Grainger and Mr. Pilcher of having refused gentlemen admittance to the museum which they have lately opened, professedly for the benefit and accommodation of their pupils, I hope you will, in accordance with your usual liberality and strict impartiality, allow an early insertion to a few observations, in refutation of a charge so totally mufounded. Immediately I perceived the accusation in question, I called upon Mr. Grainger, who assured me that it was altogether false, and that be had offered unlimited permission to all those gentlemen who would apply to him or to Mr. Pilcher. I can most positively subscribe to the accuracy of 